\title{
PERAN KEPUASAN PELANGGAN DALAM MEMEDIASI PENGARUH KUALITAS LAYANAN TERHADAP LOYALITAS PELANGGAN (STUDI PADA RUMAH MAKAN BAKMI TUNGKU DI KABUPATEN BADUNG)
}

\author{
Fahrainsyah Wahyu Putra ${ }^{1}$ \\ Eka Sulistyawati ${ }^{2}$
}

\author{
${ }^{1,2}$ Fakultas Ekonomi Universitas Udayana (Unud), Bali, Indonesia \\ e-mail:fahrain13@gmail.com
}

\begin{abstract}
ABSTRAK
Penelitian ini bertujuan untuk menjelaskan pengaruh kualitas layanan terhadap kepuasan pelanggan dan loyalitas pelanggan, pengaruh kepuasan pelanggan terhadap loyalitas pelanggan, serta peran kepuasan pelanggan memediasi kualitas layanan terhadap loyalitas pelanggan. Penelitian ini dilakukan di Rumah Makan Bakmi Tungku Uluwatu, Jimbaran dengan populasi yang digunakan yaitu seluruh pelanggan di Rumah Makan Bakmi Tungku Uluwatu, Jimbaran yang telah berkunjung sebelumnya serta ukuran sampel sebesar 100 orang, perhitungan jumlah indikator dikali 5 sampai 10. Pengumpulan data dilakukan dengan menyebarkan kuesioner dan menggunakan skala Likert untuk mengukur 21 indikator dari tiga variabel penelitian. Teknik analisis yang digunakan pada penelitian ini adalah path analysis (analisis jalur). Hasil penelitian ini menunjukkan bahwa kualitas layanan berpengaruh positif dan signifikan terhadap loyalitas pelanggan, kualitas layanan berpengaruh positif dan signifikan terhadap kepuasan pelanggan, dan kepuasan pelanggan berpengaruh positif dan signifikan terhadap loyalitas pelanggan. Hasil penelitian juga menunjukkan bahwa kepuasan pelanggan mampu memediasi pengaruh kualitas layanan terhadap loyalitas pelanggan.
\end{abstract}

Kata kunci : kualitas layanan, kepuasan pelanggan, loyalitas pelanggan

\begin{abstract}
This study aims to explain the effect of service quality on customer satisfaction and customer loyalty, the influence of customer satisfaction on customer loyalty, and the role of customer satisfaction mediate the quality of service to customer loyalty. This research was conducted at Rumah Makan Bakmi Tungku Uluwatu, Jimbaran with the population that is used by all customers in Rumah Bakmi Tungku Uluwatu, Jimbaran which visited before and the sample size of 100 people, the calculation of the indicator number multiplied 5 to 10. Data collection is done by spreading questionnaire and using Likert scale to measure 21 indicators from three research variables. Analysis technique used in this research is path analysis (path analysis). The results of this study indicate that the quality of service has a positive and significant impact on customer loyalty, service quality has a positive and significant impact on customer satisfaction, and customer satisfaction has a positive and significant impact on customer loyalty. The results also show that customer satisfaction is able to mediate the influence of service quality on customer loyalty.
\end{abstract}

Keywords : service quality, customer satisfaction, customer loyalty 


\section{PENDAHULUAN}

Pada era globalisasi saat ini perkembangan bisnis di seluruh dunia semakin pesat, khususnya di Indonesia. Perkembangan dunia bisnis dewasa ini menjadi semakin kreatif dan inovatif. Perusahaan satu sama lain bersaing sangat ketat guna mengambil hati konsumen. Efek globalisasi juga berdampak pada taraf kehidupan masyarakat yang meningkat. Dengan kata lain bahwa ini juga berpengaruh pada pola konsumsi masyarakat dan cara memenuhi kebutuhan masing-masing. Berdasarkan fenomena tersebut, tentunya banyak dunia bisnis yang semakin kesini semakin kreatif dan inovatif. Bisnis usaha pelayanan makanan atau biasa disebut juga dengan rumah makan.merupakan salah satu bisnis usaha yang mengalami perkembangan cukup pesat dan mencerminkan gaya hidup masa kini.

Usaha pelayanan makanan merupakan suatu kegiatan yang sangat kompleks dan besar antara lain meliputi stand hot dog di pantai-pantai, kafetaria di lingkungan perkantoran, rumah makan padang, ayam bakar, restoran-restoran kelas menengah, kantin di sekolah ataupun di perguruan tinggi, dan sebagainya. Setiap Usaha mempunyai masing-masing masalah tersendiri dalam menjalankan operasinya.

Persaingan dalam dunia bisnis ini cenderung sangatlah ketat dikarenakan menjamurnya usaha bisnis rumah makan. Banyak cara dilakukan oleh para pemilik rumah makan guna meningkatkan keuntungannya. Persaingan ketat masa kini, membuat mereka para pebisnis rumah makan harus memikirkan dengan matang strategi apa yang cocok untuk digunakan. Setiap para pelaku bisnis dituntut untuk mempunyai kemampuan beradaptasi dengan lingkungan sekarang, 
yang dimana pada jaman sekarang lingkungan terus menerus berubah dan berkembang. Kemampuan berapdatasi dengan lingkungan harus dimiliki para pelaku bisnis, selain itu pelaku bisnis juga dituntut untuk lebih mempunyai kepekaan terhadap segala sesuatu perubahan yang terjadi, serta mampu merespon hal tersebut dengan cepat dan tepat. Kondisi ini memaksa para manajer pemilik rumah makan untuk segera melakukan strategi terobosan.

Pemilik usaha bisnis dapat melakukan banyak cara untuk menguasai perubahaan, salah satunya adalah dengan cara meningkatkan mutu dan kualitas dari usaha bisnis itu sendiri, serta harus juga memprioritaskan kepuaasan pelanggan. Kualitas pelayanan adalah salah satu kunci untuk bersaing dalam lingkungan bisnis yang dimana pada jaman era globalisasi saat ini tingkat persaingan semakin tinggi dan ketat. Kepuasan adalah rasa bahagia maupun kecewa dari pelanggan setelah membandingkan kesan/harapan dengan hasil yang didapat dari suatu produk (Kotler, 2005). Apabila pelanggan merasa puas, akan menciptakan hubungan emosional antara penyedia jasa dengan pelanggan. Kepuasanpelanggan inilah yang akhirnya menciptakan rasa untuk melakukan pembelian ulang produk tersebut. Penelitian yang dilakukan oleh Thongsamak (2011) menyebutkan bahwa kualitas layanan merupakan dapat menciptakan kepuasan pelanggan, karena kualitas layanan berpengaruh positf terhadap kepuasaan pelanggan.

Meningkatnya persaingan ini juga secara tidak langsung menuntut para pelaku bisnis rumah makan ini untuk selalu memperhatikan kebutuhan pelanggan atau konsumen. Griffin (2003) mengatakan bahwa apabila pelanggan atau 
konsumen merasa baik terhadap kualitas pelayanan, maka pelanggan atau konsumen tersebut akan melakukan pembelian secara berulang dan melakukan promosi word of mouth kepada saudara atau rekan-rekannya. Itulah mengapa para pelaku bisnis rumah makan ini harus sudah memikirkan akan pentingnya pelayanan. Berbicara mengenai kualitas pelayanan tentu tidak bisa lepas dari yang namanya loyalitas. Loyalitas akan muncul apabila para pelanggan atau konsumen mendapatkan apa yang mereka inginkan sehingga setelah mereka menggunakan produk tersebut mereka akan mendapatkan pengalaman yang akan mendorong mereka untuk melakukan pembelian secara berulang dan pada akhirnya timbul rasa loyal terhadap produk tersebut. Hasil penelitian serupa dengan yang diperoleh Akbar (2009) yang menyatakan bahwa kualitasapelayanan berpengaruhterhadap loyalitaspelanggan. Begitu pula dengan apa yang dikatakan oleh para ahli mengenai loyalitas, bahwa loyalitas adalah perilaku pembelian secara berulang pada merek atau produk tertentu. Supriyatmini (2005) juga mengungkapkan bahwa loyalitas ialah kesetiaan pembelian kembali dengan produk yang sudah memberikan pelayanan terbaik. Kualitas layanan sangatlah penting untuk membentuk loyalitas pelanggan. Loyalitas pelanggan sangat diperlukan oleh para pelaku bisnis yang dalam hal ini adalah para manajer rumah makan guna menjalin hubungan dengan para konsumen dalam jangka panjang. Para manajer harus memperhatikan hal ini karena pada era modern jaman sekarang, mendapatkan konsumen baru tentunya akan lebih susah dan mahal daripada merawat konsumen yang sudah ada. Konsumen yang mempunyai rasa loyalitas yang tinggi tentunya telah mendapatkan kepuasan yang mereka inginkan. 
Hubungan antara kepuasan dengan kualitas layanan terhadap loyalitas para penulis sudah banyak memberi bukti berkorelasi positif . Seperti penelitiana yang sudah dilakukan oleh Akbar dengan Parves (2009) menunjukkan bahwa kepuasan bisa menjadi variable mediasi kualitas layanan terhadap loyalitas pelanggan.

Alasan penulis memilih bisnis makanan karena makanan merupakan kebutuhan pokok manusia. Bisnis makanan membuka peluang usaha yang sangat besar. Usaha di bidang kuliner sudah mengalami perkembangan pesat. Saat ini makanan tidak hanya untuk memberikan rasa kenyang bagi yang mengkonsumsinya tetapi juga telah menjadi tujuan wisata yakni wisata kuliner.

Bali merupakan salah satu provinsi yang sangat terkenal di Indonesia bahkan di dunia. Provinsi Bali sendiri terkenal dengan keindahan alam dan keanekaragaman budayanya, hingga mampu dikenal hingga kancah mancanegara. Di Provinsi Bali tepatnya di daerah badung, bisnis warung makan mengalami perkembangan pesat. Alasan peneliti memilih badung sebagai lokasi penelitian karena di kabupaten badung terdapat banyak lokasi wisata. Lokasi wisata tentu akan berpengaruh terhadap wisata kuliner. Di kabupaten badung dengan jumlah Penduduk 616.400 jiwa juga didominasi oleh anak muda. Anak muda cenderung suka berwisata dan mencoba sesuatu yang baru sehingga akan berpengaruh positif terhadap wisata kuliner.

Rumah makan Bakmi Tungku tersedia bermacam makaman dan minum khas Jawa Timur, seperti nasi goreng, nasi goreng mawut, bakmi goreng, bakmi kuah, dan sebagainya. Rumah makan ini berdiri sejak tahun 2013. Sejak tahun didirikannya, rumah makan ini memiliki 2 cabang, yang dimana pada cabang I 
(pertama) terletak di Jalan Bypass Nusadua, sedangkan cabang ke-II (kedua) terletak di jalan uluwatu Jimbaran. Alasan peneliti memilih Bakmi Tungku karena bakmi tungku dimasak dengan menggunakan peralatan tradisional yakni tungku yang dipadukan dengan bumbu khas jawa timur sehingga memberikan cita rasa yang berbeda dari mie umumnya dan memiliki harga yang terjangkau untuk berbagai kalangan. Kelebihan bakmi tungku tersebut ternyata menyisakan berbagai permasalahan. Peneliti mendapatkan hasil bahwa sebanyak 59\% pelanggan mengeluhkan tentang kualitas karyawan di Rumah Makan Bakmi Tungku, 23\% tentang waktu pelayanan, 10\% tentang fasilitas fisik, serta yang terendah $8 \%$ terkait dengan kebersihan lingkungan sekitar.

Secara kuantitas juga pengunjung Rumah Makan Bakmi Tungku cabang II lebih sedikit dibandingkan cabang I. Kuantitas pengunjung yang berbeda membuat peneliti tertarik untuk meneliti kasus ini dengan tema Peran Kepuasan Pelanggan Kualitas Layanan Terhadap Loyalitas Pelanggan. Menurut penelitian yang telah dilakukanoleh Lee (2013) memperlihatkan kualitaslayanan memiliki pengaruh yang positif dan signifikan dengan kepuasan pelanggan. MenurutAryani dan Febrina (2010) memperlihatkan bahwa kualitaslayanan memiliki pengaruh yang positf terhadap kepuasan pelanggan. Demikian pula Siddiqi (2011) mengatakan bahwa kualitas layanan memiliki pengaruh positifdan signifikan terhadap kepuasan pelanggan

Berdasarkan pada hasil kajian pustaka tersebut dibangunhipotesis sebagai berikut:

$\mathrm{H}_{1} \quad$ : Kualitas Layanan berpengaruh positif dan signifikan terhadap 


\section{Kepuasan pelanggan}

Menurut Muh.Dona Azis (2014) menyebutkan bahwa kualitas layanan adalah faktor untuk konsumen atau pelanggan membeli atau menggunakan kembali jasa tersebut. Demikian juga penelitian diadakan oleh Lee (2013) yang memperlihatkan kualitaslayanan perusuhaan berpengaruh positifdan signifikan terhadap loyalitaspelanggan. Menurut Arab et al.(2012) dalam penelitiannya memperlihatkan kualitas layanan berpengaruh positif dan signifikan terhadap loyalitas pelanggan.

Berdasarkan pada hasil kajian pustaka,dibangun hipotesa sebagai berikut :

$\mathrm{H}_{2}$ : Kualitas Layanan berpengaruh positif dan signifikan terhadap Loyalitas Pelanggan

Penelitian yang dilakukan oleh Liu et al. (2012) menunjukkan hasil bahwa kepuasanpelanggan mempunyai pengaruh yang positif terhadaployalitas pelanggan. Menurut Aryani dan Febrina (2010) dalam penelitianya juga menunjukkan bahwa kepuasanpelanggan dapat memediasi antara kualias layanan dengan loyalitaspelanggan

Berdasarkan pada hasil kajian pustaka tersebut dibangun hipotesis sebagai berikut $\mathrm{H}_{3}$ : Kepuasan pelanggan berpengaruh positif dan signifikan terhadap Loyalitas Pelanggan

Penelitian yang dilakukan Aryani danFebrina (2010) mengungkapkan kepuasan pelanggan mampu memediasi pengaruh kualitas layanan terhadap loyalitaspelanggan. Begitupun dengan peneltian Akbar (2009) menunjukkan 
bahwa kepuasan mampu memediasi kualitas layanan terhadap loyalitaspelanggan secara positif dan signifikan.

Penelitian dari Malik (2012) juga menunjukkan hasil yang sama yaitu kepuasan pelanggan berpengaruh positifdan signifikan dalam memediasi pengaruhkualitas layanan dengan loyalitaspelanggan. Kepuasan sangatlah berperan besar dalam kaitannya sebagai mediasi antara kualitas layanan dengan loyalitas pelanggan menurut Sighn dan Thakur (2012).

Berdasarkan pada kajian pustaka, dibangun hipotesa berikut :

$\mathrm{H}_{4}$ : Kepuasan Pelanggan memediasi pengaruh Kualitas Layanan terhadap Loyalitas Pelanggan

\section{METODE PENELITIAN}

Jenis data dalam penelitian adalah datakuantitatif. Data kuantitatif yang digunakan merupakan usia responden, dan hasil data kuisioner Peran Kepuasan memediasi Kualitas Layanan terhadap Loyalitas Pelanggan. Lokasi penelitian adalah Rumah Makan Bakmi Tungku Uluwatu yang bertempat di Jalan Uluwatu Jimbaran - Bali.

Sumber data yang dipergukan dalam penelitian ini merupakan data primer. Data primer yang dipergunakan dalam proses penelitian adalah persepsi konsumen mengenai objek penelitian sesuai dengan indikator yang digunakan dalam penelitianaini.. 
Populasi penelitian ini adalah semua pelanggan yang pernah datang di rumah makan Bakmi Tungku Uluwatu, Jimbaran. Metode penentuan sample yang dipergunakan didalam penelitian adalah non-probability sampling.

Metode pengumpulan data dalam proses penelitian dilakukan metode survey dengan teknik wawancara menggunakan kuisioner. Selanjutnya kuisioner dalam penelitian ini diukur dengan skala Semantic Differential. (Sugiyono, 2012). Butir-butir pertanyaan diukur melalui sekalalikert yang mana dari jawaban setiap pertanyaan memiliki skor dari yang paling negatif sampai dengan paling positif dan masing-masing penilaian diberi skor agar mempermudah penelitian ini.

\section{Analisis Jalur ( Path Analysis )}

Teknik analisis yang dipergunakan adalah teknik analisis jalur(path analysis). Analisis jalur ialah suatu bentuk perluasana analisa regresi linear berganda (Ghozali, 2007). Model ini dipergunakan untuk menganalisa pola dari suatu hubungan antar variable yang bertujuan mengetahui pengaaruh langsung antar variable.

\section{HASIL DAN PEMBAHASAN}

Rumah makan Bakmi Tungku merupakan rumah makan yang menyediakan menu makanan dan minuman yang memiliki cita rasa khas daerah Jawa Timur. Rumah makan dengan interiornya yang sederhana merupakan satusatunya rumah makan di daerah Kuta Selatan yang menggunakan tungku sebagai alat masaknya. Hal itulah yang menjadi salah satu ciri khas yang melekat dan kuat pada Rumah Makan Bakmi Tungku. Rumah makan ini berdiri sejak tahun 2013 oleh bapak Ir.Denny Wahyudi yang mempunyai motivasi untuk mrmbuka rumah 
makan dengan ciri khas Jawa Timur yang dimana beliau melihat peluang yang besar dalam hal itu. Pada awalnya didirikannya Rumah Makan Bakmi Tungku didirikan di daerah perumahan Taman Griya yang dimana lokasinya sangat tidak layak untuk menjadi tempat usaha. Akhirnya pada awal 2014 rumah makan ini pindah dari yang awalnya di dalam perumahan Taman Griya Jimbaran berpindah ke jalan bypass Nusadua (sebelah Oakley).

Seiring berjalannya waktu, rumah makan ini terus berkembang dan banyak dikunjungi oleh konsumen karena memiliki kualitas rasa makanan yang sangat khas dan harganya juga sangat terjangkau khusunya bagi kalangan pegawai dan mahasiswa. Berselang sekitar 2 tahun, akhirnya pada tahun 2016 Rumah Makan Bakmi Tungku membuka cabang keduanya yang bertempat di daerah Uluwatu.

\section{Deskripsi Variabel Penelitian}

Deskripsi variabel penelitian menunjukkan penilaian responden terhadap pernyataan - pernyataan yang terkandung dalam kuesioner. Bobot nilai dengan rentang 1 sampai 5 yang digunakan untuk menilai pernyataan dalam kuesioner kemudian diformulasikan ke dalam beberapa interval kelas yang akan menjadi dasar dalam menentukan kategori penentu rata - rata jawaban dari responden dalam penelitian. Ketentuan dalam menentukan kelas interval, yaitu :

$$
\begin{aligned}
& c=R / k \\
& c=\frac{5-1}{5} \\
& c=0,8
\end{aligned}
$$

Keterangan :

$\mathrm{c}=$ interval kelas 
$\mathrm{R}=$ nilai data tertinggi - nilai data terendah

$\mathrm{k}=$ banyaknya interval kelas sebagai berikut :

Untuk mengetahui penilaian dari variabel-variabel yang digunakan pada penelitian ini secara menyeluruh digunakan kriteria skor berikut ini :

$$
\begin{aligned}
& 1,00-1,79=\text { Sangat tidak baik } \\
& 1,80-2,59=\text { Tidak baik } \\
& 2,60-3,39=\text { Cukup baik } \\
& 3,40-4,19=\text { Baik } \\
& 4,20-5,00=\text { Sangat Baik }
\end{aligned}
$$

\section{Kualitas Layanan}

Variabel kualitas layanan dalam penelitian ini mempunyai 5 dimensi dan 15 indikator yang ditanggap memakai 5 pion sekala likert. Tanggapan responden dengan terperinci dapat dilihat diTabel berikut.

Tabel 2. Penilaian Responden terhadap Variabel Kualitas Layanan (Daya Tanggap)

\begin{tabular}{cccccccc}
\hline Indikator & \multicolumn{4}{c}{ Distribusi Jawaban } & & $\begin{array}{c}\text { Skor } \\
\text { Total }\end{array}$ & $\begin{array}{c}\text { Rata- } \\
\text { rata }\end{array}$ \\
\cline { 2 - 6 } & 1 & 2 & 3 & 4 & 5 & & \\
\hline Kecepatan pelayanan & 0 & 44 & 26 & 25 & 5 & 291 & 2,91 \\
Kesiapan pelayanan & 0 & 39 & 23 & 33 & 5 & 304 & 3,04 \\
Teliti dalam pelayanan & 0 & 17 & 34 & 40 & 9 & 341 & 3,41 \\
\hline Rata-rata & & & & & & & $\mathbf{3 , 1 2}$
\end{tabular}

Sumber : data diolah, 2017

Tabel 2. Memperlihatkan ratarata nilai para respondend dengan variable kualitas layanan dalam dimensi daya tanggap beserta indikatornya. Skor total tertinggi berada pada indikator teliti dalam pelayan yang menunjukkan bahwa 
karyawn Rumah Makan Bakmi Tungku Uluwatu Jimbaran sangat teliti dalam melayani pelanggannya. Kemudian dilanjutkan oleh kesiapan pelayanan dengan skor total 304, kecepatan pelayanan dengan skor total 304, dan kecepatan pelayanan dengan skor total terendah yaitu 291. Dengan skor total 291 pada indikator kecepatan pelayanan menunjukkan bahwa karyawan Rumah Makan Bakmi Tungku perlu meningkatkan lagi kecepatan dalam pelayanannya dalam melayani pelanggan atau konsumennya. Untuk dimensi daya tanggap mendapatkan skor rata-rata 3,12 yang termasuk dalam kategori cukupbaik. Ini memperlihatkan bahwa umumnya karyawan Rumah Makan Bakmi Tungku Uluwatu Jimbaran memiliki daya tanggap yang cukup baik dalam melayani pelanggannya dan menjalankan usahanya.

Tabel 3. Penilaian Responden terhadap Variabel Kualitas Layanan (Kehandalan)

\begin{tabular}{|c|c|c|c|c|c|c|c|}
\hline \multirow[t]{2}{*}{ Indikator } & \multicolumn{5}{|c|}{ Distribusi Jawaban } & \multirow{2}{*}{$\begin{array}{l}\text { Skor } \\
\text { Total }\end{array}$} & \multirow{2}{*}{$\begin{array}{l}\text { Rata- } \\
\text { rata }\end{array}$} \\
\hline & 1 & 2 & 3 & 4 & 5 & & \\
\hline Ketepatan waktu & 0 & 30 & 31 & 36 & 3 & 312 & 3,12 \\
\hline Pelayanan yang adil & 0 & 12 & 23 & 54 & 11 & 364 & 3,64 \\
\hline Rata-rata & & & & & & & 3,38 \\
\hline
\end{tabular}

Sumber : data diolah, 2017

Tabel 3. Memperlihatkan rerata penilai dari semua respondend terhadap variable kualitas layanan dalam dimensi kehandalan beserta indikatornya. Skor total tertinggi pada indikator pelayanan yang adil yang menunjukkan bahwa karyawan rumah makan Bakmi Tungku Uluwatu Jimbaran mampu melayani pelanggannya dengan adil dan handal. Sedangkan skor total terendah yaitu indikator ketepatan waktu dengan skor total 312. Skor total 312 pada indikator 
ketepatan waktu menujukkan bahwa karyawan Rumah Makan Bakmi Tungku Uluwatu Jimbaran perlu memperhatikan ketepatan waktu dalam rangka melayani para pelanggannya. Untuk dimensi kehandalan mendapatkan skor rata-rata 3,38 yang termasuk dalam kategori lumayan baik. Ini memperlihatkan bahwa umumnya karyawan Rumah Makan Bakmi Tungku Uluwatu Jimbaran memiliki kehandalan yang cukup baik dalam melayani pelanggannya dan menjalankan usahanya.

Tabel 4. Penilaian Responden terhadap Variabel Kualitas Layanan (Empati)

\begin{tabular}{lccccccc}
\hline \multicolumn{1}{c}{ Indikator } & \multicolumn{4}{c}{ Distribusi Jawaban } & & $\begin{array}{c}\text { Skor } \\
\text { Total }\end{array}$ & $\begin{array}{c}\text { Rata- } \\
\text { rata }\end{array}$ \\
\cline { 2 - 6 } & 1 & 2 & 3 & 4 & 5 & & \\
\hline Memahami kebutuhan khusus & 0 & 6 & 25 & 64 & 5 & 368 & 3,68 \\
Memberikan kompensasi & 0 & 14 & 15 & 58 & 13 & 370 & 3,7 \\
Sikap ramah karyawan & 0 & 10 & 21 & 57 & 12 & 371 & 3,71 \\
Memberikan perhatian secara & 0 & 6 & 16 & 66 & 12 & 384 & 3,84 \\
individual & & & & & & &
\end{tabular}

\begin{tabular}{lr}
\hline Rata-rata & $\mathbf{3 , 7 3}$
\end{tabular}

Sumber : data diolah, 2017

Tabel 4. memperlihatkan rerata penilaian respondend terhadap variable kualitas layanan dalam dimensi empati beserta indikatornya. Skor total tertinggi pada indikator memberikan perhatian secara individual yang menunjukkan bahwa karyawan Rumah Makan Bakmi Tungku Uluwatu Jimbaran mampu memberikan perhatian secara individual kepada pelanggannya dengan sangat baik. Kemudian dilanjutkan oleh sikap ramah karyawan dengan skor total 371, memberikan kompensasi pelanggan dengan skor total 370, dan memberikan kompensasi dengan skor total terkecil yaitu 368. Dengan skor total 368 pada memahami 
kebutuhan khusus pelanggan menunjukkan bahwa karyawan Rumah Makan Bakmi Tungku Uluwatu Jimbaran perlu meningkatkan perhatian khusus kepada pelanggannya. Untuk dimensi empati mendapatkan skorrata-rata 3,73 yangtermasuk dalam kategori biak. Hal memperlihatkan umumnya karyawan Rumah Makan Bakmi Tungku Uluwatu Jimbaran memiliki kehandalan yang baik dalam melayani pelanggannya dan menjalankan usahanya.

Tabel 5. Penilaian Responden terhadap Variabel Kualitas Layanan (Jaminan)

\begin{tabular}{|c|c|c|c|c|c|c|c|}
\hline Indikator & & & & & & Skor & Rata- \\
\hline & 1 & 2 & 3 & 4 & 5 & Total & rata \\
\hline Cara karyawan berkomunikasi & 0 & 18 & 29 & 48 & 5 & 340 & 3,4 \\
\hline Pengetahuan karyawan tentang & & & & & & & \\
\hline produk & 0 & 10 & 12 & 65 & 13 & 381 & 3,81 \\
\hline Rata-rata & & & & & & & 3,61 \\
\hline Sumber : data diolah, 2017 & & & & & & & \\
\hline Tabel 5. Memperl & natka & rera & enila & resp & end & hadap & variable \\
\hline kualitas layanan dalam dir & ensi & $\min$ & esert & dikat & ya. $S$ & total & ertinggi \\
\hline pada indikator pengetahua & tent & $n g p$ & k ya & nenu & kkan & hwa k & aryawan \\
\hline Rumah Makan Bakmi Tı & ngku & Uluw & Jiml & me & iki p & getahu & in yang \\
\hline baik dalam produk yang & ditau & rrkan & dika & cara & yawa & berkon & nunikasi \\
\hline memiliki skor total tere & dah & raitu & ya & dima & men & jukkan & bahwa \\
\hline karyawan Rumah Makan & Bakm & Tun & Ulu & Jim & an $\mathrm{pe}$ & $\mathrm{u}$ mem & perbaiki \\
\hline
\end{tabular}


lokal. Untuk dimensi jaminan mendapatkan skor rerata 3,61 yang termasuk kategori baik. Hal memperlihatkan umumnya karyawan Rumah Makan Bakmi Tungku Uluwatu Jimbaran mampu memberikan jaminan yang baik kepada para pelanggannya.

Tabel 6. Penilaian Responden terhadap Variabel Kualitas Layanan

(Bukti Fisik)

\begin{tabular}{cccccccc}
\hline Indikator & \multicolumn{4}{c}{ Distribusi Jawaban } & Skor & $\begin{array}{c}\text { Rata- } \\
\text { Total }\end{array}$ & rata \\
\cline { 2 - 5 } & 1 & 2 & 3 & 4 & 5 & 352 & 3,52 \\
Sarana Parkir & 0 & 19 & 23 & 45 & 13 & 35 \\
Dekorasi Ruangan & 0 & 4 & 19 & 55 & 22 & 395 & 3,95 \\
Fasilitas fisik & 0 & 5 & 14 & 62 & 19 & 395 & 3,95 \\
Penampilan karyawan & 0 & 8 & 16 & 55 & 21 & 389 & 3,89 \\
\hline Rata-rata & & & & & & & $\mathbf{3 , 8 3}$ \\
\hline
\end{tabular}

Sumber : data diolah, 2017

Tabel 6. Memperlihatkan rerata penilaian respondend terhadap variable kualitas layanan dalam dimensi bukti fisik beserta indikatornya. Skor total tertinggi pada indikator dekorasi ruangan dan fasilitas fisik yang menunjukkan bahwa Rumah Makan Bakmi Tungku Uluwatu Jimbaran mempunyai dekorasi ruangan dan fasilitas fisik yang sangat baik. Indikator penampilan karyawan memperoleh skor total 389 dan sarana parkir memperoleh skor total terkecil yaitu 352. Dengan skor total 352 pada indikator sarana parkir mengartikan bahwa Rumah Makan Bakmi Tungku perlu memperluas atau memperbaiki lahan parkir yang ada demi kenyamanan para pelangannya. Lahan kosong di seberang jalan Rumah Makan Bakmi Tungku Uluwatu bisa menjadi opsi yang baik bagi manajer untuk mengubahnya menjadi lahan parkir untuk pengunjung. Untuk dimensi bukti fisik mendapatkan sekor ratarata 3,83 yang termasuk dalamkategori baik. Hal ini 
memperlihatkan umunya Rumah Makan Bakmi Tungku Uluwatu Jimbaran mampu memberikan kesan bukti fisik yang baik untuk pelanggannya.

\section{Kepuasan Pelanggan}

Variabel kepuasan pelanggan didalam penelitian ini merupakanvariabel bebas yang di ukur menggunakan 3 indikator yang ditanggapi memakai 5 point skala likert. Tanggapan dari para respondend secara terperinci dapat diamati diTabel berikut.

Tabel 7. Penilaian Responden terhadap Variabel Kepuasan Pelanggan

\begin{tabular}{lccccccc}
\hline \multicolumn{1}{c}{ Indikator } & \multicolumn{5}{c}{ Distribusi Jawaban } & $\begin{array}{c}\text { Skor } \\
\text { Total }\end{array}$ & $\begin{array}{c}\text { Rata- } \\
\text { rata }\end{array}$ \\
\cline { 2 - 6 } & 1 & 2 & 3 & 4 & 5 & 326 & 3,26 \\
\hline $\begin{array}{l}\text { Pelayanan yang cepat dan } \\
\text { tepat }\end{array}$ & 0 & 28 & 28 & 34 & 10 & 326 \\
$\begin{array}{l}\text { Puas memilih dan } \\
\text { menggunakan produk }\end{array}$ & 0 & 5 & 20 & 59 & 16 & 386 & 3,86 \\
$\begin{array}{l}\text { Puas dengan hasil akhir yang } \\
\text { diterima }\end{array}$ & 0 & 9 & 16 & 55 & 21 & 391 & 3,91 \\
\hline
\end{tabular}

\begin{tabular}{lc}
\hline Rata-rata & 3,66
\end{tabular}

Sumber : data diolah, 2017

Tabel 7. Memperlihatkan ratarata nilai respondend terhadap kepuasan pelanggan beserta indikatornya. Skor tertinggi berada pada indikator puas dengan hasil yang diterima dengan skor 391, ini menunjukkan bahwa para pelanggan dari Rumah Makan Bakmi Tungku Uluwatu Jimbaran merasa puas dan mendapatkan pengalaman dengan hasil yang diterima dari mengunjungi dan mengkonsumsi produk yang ditawarkan oleh Rumah Makan Bakmi Tungku Uluwatu Jimbaran. Selanjutnya indikator puas memilih dan menggunakan produk dengan skor total 386 dan indikator pelayanan yang cepat dan tepat dengan skor total 326. Indikator 
dengan perolehan skor total terendah sebanyak 326 menunjukkan bahwa para pelanggan Rumah Makan Bakmi Tungku Uluwatu Jimbaran sangat sensitif terhadap kecepatan dan ketepatan pelayananan yang diberikan. Oleh karena itu karyawan Rumah Makan Bakmi Tungku Uluwatu Jimbaran harus segera membenahi hal ini demi kepuasan para pelanggannya. Variabel kepuasan pelanggan mendapat skor rata-rata 3,66 yang termasuk dalam kategori cukup baik. Hal ini memiliki arti, umumnya Rumah Makan Bakmi Tungku Uluwatu Jimbaran mampu memberikan kepuasan pelanggan yang baik bagi pelanggannya.

\section{Loyalitas Pelanggan}

Variable loyalitas pelanggan didalam proses penelitian ini merupakan variable bebas yang diukur menggunakan 3 indikator yang ditanggapi memakai 5 point skala likert. Tanggapan para respondend secara terperinci bisa dilihat padaTabel berikut.

Tabel 8. Penilaian Responden terhadap Variabel Loyalitas Pelanggan

\begin{tabular}{|c|c|c|c|c|c|c|c|}
\hline \multirow[t]{2}{*}{ Indikator } & \multicolumn{5}{|c|}{ Distribusi Jawaban } & \multirow{2}{*}{$\begin{array}{l}\text { Skor } \\
\text { Total }\end{array}$} & \multirow{2}{*}{$\begin{array}{l}\text { Rata- } \\
\text { rata }\end{array}$} \\
\hline & 1 & 2 & 3 & 4 & 5 & & \\
\hline $\begin{array}{l}\text { Merekomendasikan kepada } \\
\text { orang lain }\end{array}$ & 0 & 35 & 13 & 40 & 12 & 329 & 3,29 \\
\hline $\begin{array}{l}\text { Melakukan pembelian secara } \\
\text { berulang }\end{array}$ & 0 & 6 & 21 & 53 & 20 & 387 & 3,87 \\
\hline Tidak mudah berpindah & 0 & 11 & 35 & 39 & 15 & 358 & 3,58 \\
\hline Rata-rata & & & & & & & 3,58 \\
\hline
\end{tabular}

Sumber : data diolah, 2017

Tabel 8. Memperlihatkan rerata penilaian respondend terhadaployalitas pelanggan beserta indikatornya. Skor total tertinngi berada pada indikator melakukan secara berulang yaitu 367. Hal ini menunjukkan bahwa para pelanggan 
Rumah Makan Bakmi Tungku sangat puas terhadap produk yang diterima dari mengkonsumsi Rumah Makan Bakmi Tungku Uluwatu Jimbaran. Kemudian indikator tidak mudah berpindah dengan skor total 358 dan skor total terkecil dipegang oleh indikator merekomendasikan kepada orang lain dengan skor total 329. Dengan skor total 329 pada indikator merekomendasikan kepada orang lain menunjukkan bahwa para pelanggan yang sudah sering datang ke Rumah Makan Bakmi Tungku Uluwatu Jimbaran tidak ingin atau belum ingin merekomendasikan Rumah Makan Bakmi Tungku Uluwatu Jimbaran kepada orang lain karena berbagai faktor. Variabel loyalitas pelanggan mendapat skor rata-rata 3,58 yang termasuk dalamakategori baik. Hal ini memiliki arti, umumnya Rumah Makan Bakmi Tungku Uluwatu Jimbaran mampu membuat para pelanggan merasa loyal dengan baik.

\section{Hasil Analisis Jalur}

Metode analisis jalura(path analysis) merupakan perluasanadari metode regresialinear bergandaauntuk menguji hubunganakausalitas antar dua ataualebih variabel. Adapun tahapan dalam pengujian dengan teknik analisis ini yaituasebagai berikut ;

\section{Merumuskan hipotesis dan persamaan struktural}

a) Kualitas Layanan (X) berpengaruh positif terhadap Loyalitas Pelanggan (Y) Perhitungan koefisienPath dilakukan dengan melakukan analisa regresi melalui software SPSS 17.0 dan hasil dari analisis tersebut disajikan dalam Tabel berikut. 
Tabel 9. Hasil Analisis Jalur Persamaan Regresi 1

\begin{tabular}{|c|c|c|c|c|c|c|}
\hline & \multirow[t]{2}{*}{ Model } & \multicolumn{2}{|c|}{ Unstandardized Co. } & \multirow{2}{*}{$\begin{array}{c}\text { Standardized } \\
\text { Co. }\end{array}$} & \multirow[t]{2}{*}{$\mathrm{T}$} & \multirow[t]{2}{*}{ Sig. } \\
\hline & & $B$ & $\begin{array}{l}\text { Std. } \\
\text { Error }\end{array}$ & & & \\
\hline \multirow[t]{3}{*}{1} & (Constant) & 0 & 0,066 & & 0 & 1 \\
\hline & REGR factor & 0,757 & 0,066 & 0,757 & 11,46 & 0 \\
\hline & score $X$ & & & & 8 & \\
\hline
\end{tabular}

Sumber : data diolah, 2017

Berdasarkan pada hasil Analisa jalur substruktur 1 padaTabel 9. tersebut, maka bisa disusun persamaan struktur sebagai berikut :

$M=\beta_{1} X+e_{1}$

$\mathrm{M}=0,757 \mathrm{X}+\mathrm{e}_{1}$

b) Kualitas Layanan (X) berpengaruh positifterhadap KepuasanPelanggan (M)

c) Kualitas Layanan (X) berpengaruh positifterhadap LoyalitasPelanggan (Y) melalui Kepuasan Pelanggan (M)

Penghitungan kofisien Path dilakukan melalui penganalisaan regresi melalui software SPSS 17.0 dan hasil dari analisis tersebut disajikan dalam Tabel 10. berikut.

Tabel 10. Hasil Analisis Jalur Persamaan Regresi 2

\begin{tabular}{|c|c|c|c|c|c|c|}
\hline \multirow{2}{*}{\multicolumn{2}{|c|}{ Model }} & \multicolumn{2}{|c|}{ Unstandardized Co. } & \multirow{2}{*}{$\begin{array}{c}\text { Standardized } \\
\text { Co. } \\
\text { Beta }\end{array}$} & \multirow[t]{2}{*}{$\mathrm{T}$} & \multirow[t]{2}{*}{ Sig. } \\
\hline & & B & Std. Error & & & \\
\hline \multirow[t]{3}{*}{1} & (Constant) & 000 & 0,060 & & 000 & 1,000 \\
\hline & REGR factor score $X$ & 0,298 & 0,093 & 0,298 & 3,207 & 0,002 \\
\hline & REGR factor score $M$ & 0,552 & 0,093 & 0,552 & 5,937 & 000 \\
\hline & 0,632 & \multicolumn{3}{|c|}{ Sig. F : 0,001 } & & \\
\hline
\end{tabular}

Sumber : data diolah, 2017 
Berdasarkan analisis substruktur 2 pada Tabel 10 tersebut, makadapat disusun persamaanstruktur sebagai berikut.

$$
\begin{aligned}
& Y=\beta_{2} X+\beta_{3} Y+e_{2} \\
& Y=0,298 X+0,552 Y+e_{2}
\end{aligned}
$$

\section{Bentuk diagram koefisien jalur}

Sebelum melakukan penyusunan modle diagaram jalur akhir, lebih dulu dihitung nilaistandar error sebagaiberikut.

$$
\begin{aligned}
& \mathrm{e}=\sqrt{1-\mathrm{R} 1}{ }^{2} \\
& \mathrm{e}_{1}=\sqrt{1-R 1}{ }^{2}=\sqrt{1-0,757}=0,5 \\
& \mathrm{e} 2=\sqrt{1-R 2}^{2}=\sqrt{1-0,632}=0,608
\end{aligned}
$$

Berdasarkan perhitunganpengaruh error (e), didapatkan sebuah hasil berupa pengaruh error $\left(\mathrm{e}_{1}\right)$ sebesar 0,5 danpengaruh error $\left(\mathrm{e}_{2}\right)$ sebesar 0,608

. Hasil koefisiendeterminasi total sebagai berikut :

$$
\begin{aligned}
\mathrm{R}^{2} \mathrm{~m} & =1-\left(\mathrm{Pe}_{1}\right)^{2}\left(\mathrm{Pe}_{2}\right)^{2} \\
& =1-(0,5)^{2}(0,608)^{2} \\
& =1-(0,25)(0,370) \\
& =1-0,093=0,91
\end{aligned}
$$

Nilai determinasitotal sebesar 0,91 memiliki arti bahwa sebesar91\% variasi loyalitaspelanggan dipengaruhi oleh variance kualitas layanan dan kepuasan pelanggan, sedangkan sisanya yaitu sebesar $9 \%$ dijelaskan oleh factor lainnya yang tidak dimasukkan kedalam model. 
Hasil koefisien jalur pada hipotesa penelitian bisa digambarkan pada

\section{Menghitung koefisien jalur secara simultan (Uji F)}

Tabel 4.18 memperlihatkan variable bebas dalam penelitian berpengaruh terhadapvariabel terikat. Tingkat signifikansi yaitu $0,001<0,05$ maka diberikan kesimpulanbahwa variabel kualitas pelayanan dan kepuasan dari pelanggan berpengaruh secara simultan terhadapvariabel loyalitas pelanggan. Kesimpulan ini aadalah model persaman strcktural telah memenuhi persyarat Goodnessof Fit melalui uji F.

\section{Menghitung koefisien jalur secara parsial (Uji T)}

Kriteria pengujian dalam menjelaskan interperetasi sebuah pengaruhantar masing - masing variabel adalah sebagai berikut :

Jika sig. $\mathrm{t}<0,05$ maka $\mathrm{H}_{0}$ ditolak dan $\mathrm{H}_{1}$ diterima

Jika sig. $\mathrm{t}>0,05$ maka $\mathrm{H}_{0}$ diterima dan $\mathrm{H}_{1}$ ditolak

a) Pengaruh kualitas layanan terhadap kepuasan pelanggan

H0 : Kualitaslayanan tidak berpengaruh terhadap kepuasanpelanggan

H1 : Kualitas pelayanan berpengaruh positif terhadap kepuasanpelanggan Hasil uji yang tertera pada Tabel menunjukkan bahwahubungan antara variable kwalitas layanan terhadap kepwasan pelangan memperoleh nilai signifikan ssebesar 0,000 dengan nilai koefisienbeta sebesar 0,757. Hasil ini memiliki arti kualitas layanan berpengaruhpositif dan signifikan terhadap kepuasanpelanggan.

b) Pengaruh kualitas layananterhadap loyalitas pelangan

$\mathrm{H}_{0}$ : Kualitas layanan tidak berpengaruhterhadap loyalitasapelanggan 
$\mathrm{H}_{1}$ : Kualitas layanan berpengaruh positif terhadap loyalitaspelanggan

Tabel menunjukkan bahwa hubungan antara variabel keunggulan bersaing terhadap kinerja pemasaran memperoleh nilaisignifikansi sebesar 0,001 dengan nilai koefisien betasebesar 0,298. Hasil ini memiliki arti kualitas layanan memiliki pengaruhpositif dan signifikan terhadap loyalitaspelanggan.

c) Pengaruh kepuasanpelanggan terhadap loyalitaspelanggan

$\mathrm{H}_{0}$ : Kepuasa pelangan tidak berpengaruh positf terhaadap loyalitas pelanggan

$\mathrm{H}_{1}$ : Kepuasan pelanggan berpengaruh positifterhadap loyalitas pelanggan

Tabel menunjukkan bahwa hubungan antara variable kepuasanpelanggan terhadap loyalitaspelanggan memperoleh nilai signifikansi sebesar 0,001 dengan besar nilai koefisien betasebesar 0,552. Hasil ini memiliki arti kepuasaan pelanggan berpengaruh postifdan signifikan terhadap loyalitaspelanggan.

\section{Validasi Model Diagram Jalur Akhir}

Berdasarkan diagramjalur pada Gambar 2. maka bisa di hitung pengaruh masingmasing variable yang di rangkum didalam tabel berikut :

Tabel 11. Pengaruh Langsung, Pengaruh Tidak Langsung serta Pengaruh Total Kualitas Layanan (X), Kepuasan Pelanggan (M) dan Loyalitas Pelanggan (Y)

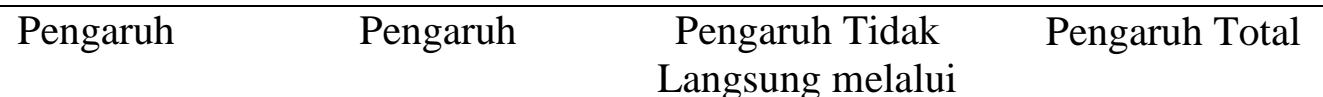




\begin{tabular}{cccc}
\hline Variabel & Langsung & $\begin{array}{c}\text { Kepuasan } \\
\text { Pelanggan }\end{array}$ \\
\hline $\mathrm{X} \rightarrow \mathrm{M}$ & 0,757 & - & 0,795 \\
$\mathrm{X} \rightarrow \mathrm{Y}$ & 0,298 & 0,417 & 0,715 \\
$\mathrm{M} \rightarrow \mathrm{Y}$ & 0,552 & - & 0,552 \\
\hline
\end{tabular}

Sumber : data diolah, 2017

Tabel 11. menunjukkan bahwa pengaruh langsung antara variabelakualitas layanan dan kepuasan dari pelanggan memiliki nilai pengaruh langsung yaitu sebesar 0,757. Antara kualitas layanan dengan loyalitas pelanggan dengan nilai pengaruh secara langsung sebesar 0,298 sedangkan nilai pengaruh secara tidak langsung melalui kepuasan pelanggan sebesar 0,417 dengan nilai pengaruh total sebesar 0,715 . Dan yang terakhir nilai pengaruh langsung antara kepuasan dari pelanggan dan loyalitaspelanggan sebesar 0,552 .

\section{Pengaruh Kualitas Layanan terhadap Kepuasan Pelanggan pada Rumah Makan Bakmi Tungku Uluwatu Jimbaran}

Penelitian ini dilakukan untuk mengetahui bagaimana pengaruh kualitas layanan terhadapkepuasan pelanggan. Hasil dari pengolahan data menunjukkan nilai koefisienbeta sebesar 0,757 dengan tingkat signifikansi $0,000(\leq 0,05)$, artinya $\mathrm{H}_{1}$ yang menyatakan kualitas layanan berpengaruh positif dan signifikan terhadap kepuasan pelanggan pada Rumah Makan Bakmi Tungku Uluwatu Jimbaran dapat diterima. Hasil ini berarti, manajer Rumah Makan Bakmi Tungku Uluwatu Jimbaran harus meningkatkan kualitas layanannya sehingga apabila kualitas layanan tersebut telah ditingkatkan dan diakui oleh konsumen maka kepuasan pelanggan akan otomatis meningkat . 
Hasil ini diperkuat hasil dari penelitian Siddiqi (2011), Febri (2012), dan Aryani dan Febrina (2010) yang juga mendapatkan hasil yang sama bahwa kualitas layanan berpengaruh positif dan signifikan terhadap kepuasan pelanggan.

\section{Pengaruh Kualitas Layanan terhadap Loyalitas Pelanggan pada Rumah Makan Bakmi Tungku Uluwatu Jimbaran}

Penelitian ini dilakukan untuk mengetahui bagaimana pengaruh oreintasi keuwirausahaan terhadap kinerja pemasaran. Hasil pengolahan data menunjukkan nilai koefisien beta sebesar 0,298 dengan tingkat signifikansi $0,001(\leq 0,05)$, artinya $\mathrm{H}_{2}$ yang menyatakan kualitas sebuah layanan berpengaruh positifdan signifikan terhadap loyalitas pelangganpada Rumah Makan Bakmi Tungku Uluwatu Jimbaran dapat diterima. Hasil ini berarti semakin tinggi kualitas layanan yang dimiliki oleh Rumah Makan Bakmi Tungku Uluwatu Jimbaran maka semakin tinggipula loyalitas pelangganterhadap rumah makan tersebut. Hasil penelitian ini diperkuat dengan hasil penelitian dari Prasastono (2016), Arab et al. (2012), dan Ellys (2008) yang juga menemukan hal yang sama bahwa kwalitas layanan berpengaruhpositif dan signifikan terhadap loyalitas pelanggan.

\section{Pengaruh Kepuasan Pelanggan terhadap Loyalitas Pelanggan pada Rumah} Makan Bakmi Tungku Uluwatu Jimbaran

Penelitian ini dilakukan untuk mengetahui pengaruh keunggulan bersaing terhadap kinerja pemasaran. Hasil olah data menunjukkan nilai koefisien beta sebesar 0,552 dengan tingkat signifikansi $0,001(\leq 0,05)$, artinya $\mathrm{H}_{3}$ yang menyatakan kepuasan pelanggan berpengaruh yang positif dan signifikan terhadap 
loyalitaspelanggan pada Rumah Makan Bakmi Tungku Uluwatu Jimbaran dapat diterima. Hasil ini berarti bahwa pemilik Rumah Makan Bakmi Tungku Uluwatu Jimbaran perlu meningkatkan kepuasan pe;anggan untuk meningkatkan loyalitas pelanggan yang ada.

Hasil penelitian ini memperkuat hasil penelitian dari Febri (2012) yang melakukan penelitian mengenai variabel kualitas layanan, kepuasan pelanggan loyalitas pelanggan, dalam penelitiannya ia menemukan kepuasan seorang pelanggan memiliki pengaruh secara positif dan signifikan terhadaployalitas pelangan. Prasastono (2016) juga menemukan hasil yang sama mengenai pengaruh antara kepuasan pelanggan dengan loyalitas pelanggan. Shanti (2015) dalam penelitiannya pada product pewangi pakaian Molto dikota Denpasarjuga menemukan bahwa kepuasanpelanggan memiliki pengaruh positif dan signifikan terhadap loyalitaspelanggan.

\section{Peran Kepuasan Pelanaggan Memediasi Pengaruh Kualitas Layanan terhadap Loyalitas Pelanggan pada Rumah Makan Bakmi Tungku Uluwatu Jimbaran}

Penelitian diadakan untuk mengetahui suatu peran keunggulan bersaing memediasi bagaimana pengaruh orientasi kewirausahaan terhadap kinerja pemasaran. Hasil olah data memperlihatkan nilai pengaruh secara tidaklangsung $(0,417)$ lebihbesar dari nilai pengaruh langsung (0,298), artinya $\mathrm{H}_{4}$ yang menyatakan kepuasan seorang pelanggan dapat memediasi sebuah pengaruh kwalitas pelayanan terhadap loyalitaspelanggan pada Rumah Makan Bakmi Tungku Uluwatu Jimbaran dapat diterima. Ini berarti pada Rumah Makan Bakmi 
Tungku Uluwatu Jimbaran suatu kepuasan pelanggan yang dimiliki dapat dijadikan sebagai mediasi dalam menciptakan loyalitas pelanggan yang baik melalui kualitas layanan. Hasil penelitian ini memperkuat hasil penelitian dari Febri (2012). Ia menemukan bahwa variable kepuasan seorang pelanggan mampu memediasi pengaruh antara kwalitas pelayanan terhadap loyalitas pelanggan.

\section{SIMPULAN DAN SARAN}

Berdasarkan pembahasan hasil dari penelitian yang telah dilakukan, maka diperoleh kesimpulan bahwa kualitas layanan berpengaruh positif dan signifikan terhadap loyalitas pelanggan, artinya apabila terjadi perubahan pada kualitas layanan maka loyalitas pelanggan juga akan mengalami perubahan. Pengaruh hubungan ini menunjukkan nilai positif yang artinya apabila kualitaslayanan yang dimiliki semakin biak, akan tercipta suatu loyalitas pelanggan yang positif pada Rumah Makan Bakmi Tungku Uluwatu Jimbaran. Hasil penelitian ini menunjukkan bahwa kualitasalayanan berpengaruh positf dan signifikan terhadap kepuasan pelangan, artinya apabila terjadi perubahan pada kualitas layanan maka kepuasan pelanggan juga akan mengalami perubahan. Pengaruh hubungan ini menunjukkan nilai positif yang artinya apabila kualitas layanan yang dimiliki smakin tinggi maka kepuasanpelanggan yang tercipta juga akan semakin baik pada Rumah Makan Bakmi Tungku Uluwatu Jimbaran, begitu sebaliknya. Hasil penelitian ini menunjukkan bahwa kepuasan pelanggan berpengaruh positif dan signifikan terhadp loyalitas pelangan, artinya apabila kepuasanpelanggan mengalami perubahan maka loyalitas pelanggn juga akan mengalami perubahan. Pengaruh hubungan ini menunjukkan nilai positif yang artinya, apabila para pemilik Rumah Makan Bakmi Tungku Uluwatu Jimbaran mampu menciptakan kepuasan pelanggan maka akan tercipta suatu loyalitas pelanggan yang diinginkan. Kepuaan pelangan mampu memediasi pengaruh kualitas layanan terhadap loyalitaspelangan. Hal ini menggambarkan bahwa pengaruh variable kualitaslayanan terhadap variable loyalitas pelanggan mengalami peningkatan dengan adanya variable kepuasan pelanggan. 
Berdasarkan hasil dan juga simpulan, memiliki saran sebagai berikut.

Peneliti menyarankan agar lahan kosong diseberang jalan Rumah Makan Bakmi Tungku Uluwatu mampu di akuisisi dan dijadikan lahan parkir untuk para pelanggan yang berkunjung. Pelayanan yang cepat dan tepat mendapatkan skor terendah dari indikator kepuasan pelanggan, yang dimana hal ini menunjukkan bahwa masalah waktu lagi-lagi menjadi hal yang sangat vital bagi karyawan Rumah Makan Bakmi Tungku Uluwatu. Melayani pelanggan dengan cepat saja tidak cukup. Ketepatan disini juga menjadi hal yang sangat penting. Melayani pelanggan dengan tepat namun tidak cepat ataupun sebaliknya akan membuat para pelanggan merasa kurang puas, sehingga disini penelti memberikan saran agar manajer Rumah Makan Bakmi Tungku lebih sering untuk mengawasi pegawainya agar nantinya mampu mengevaluasi kinerja dari para pegawainya, Merekomendasikan kepada orang lain mendapatkan skor terendah dari indikator loyalitas pelanggan. Konsumen belum ingin merekomendasikan kepada orang lain dikarenakan masih banyaknya masalah yang perlu dievaluasi oleh manajer Bakmi Tungku Uluwatu. Peneliti juga memberikan saran bahwa sebaiknya manajer memperhatikan dan meningkatkan kualitas layanan terlebih dahulu. Apabila kualitas layanan mampu diperbaikin ataupu n ditingkatkan maka pelanggan akan merasa puas setelah itu mereka akan merekomendasikan kepada orang lain atau kerabatnya.

\section{DAFTAR RUJUKAN}


Ahmed, Ishfaq., Muhammad Musarrat and Ahmed Usman. 2013. A Mediation os Customer Satisfaction Relationship between Service Quality and Repurchase Intensions for The Telecom Sector in Pakistan. African Journal of Business Management, 4 (16):3457-3462.

Bei, Lien-T adn Chiao, Yu-Ching. 2001. An Integrated Model for The Effects of Perceived Product, Perceived Service Quality, and Perceived Price Fairness on Consumer Satisfaction and Loyalty.Journal of Consumer Satisfaction, Dissatisfaction and Complaiining Behaviour. 14 (10):125-141.

Chinomona, Richard. and Dubihlela, Dorah. 2014. Does Customer Satisfaction Lead to Customer Trust, Loyalty and Repurchase Intention of Local Store Brands? The Case of Gauteng Province of South Africa.Mediterranean Journal of SocialSciences, 5 (9): 23-32.

Casalo, L.V. C.Flavian., and M. Guinaliu. 2008. The Role of Satisfaction and Website Usability in Developing Customer Loyalty and Positive Word of Mouth In The E-Banking Serivic. The International Journal of Bank Marketing, 26 (5):339-417.

Chow, Clement S. F. and Lida L. Zhang. 2008, Measuring consumer satisfaction and dissatisfaction intensities to identify satisfiers and dissatisfies,Journal of Consumer Satisfaction, Dissatisfaction and Complaining Behavior, 21 (3):66-79.

Febri.2012. Analisis Pengaruh Kualitas Pelayanan terhadap Loyalitas Konsumen dengan Kepuasan Konsumen sebagai variabel moderasi (studi kasus pada konsumen CS Kopi Tubruk Surakarta), Jurnal Ekonomi dan Kewirausahaan, 16 (2):186-233

Ganguly, Boudhayan., Dash,B,Satya., Cyr, Dianne., Head, M. 2010. The Effects of Website Design on Purchase Intention in Online Shopping The Mediating Rote of Trust and The Moderating Role of Culture. International Journal Electronic Business, 8 (4):302-334.

Mardalis A. 2011. Meraih Loyalitas Pelanggan, Jurnal Manajemen dan Bisnis, 9 (2):111-113

Maria,Vinagre. 2008. The Influence Of Service Quality And Patients' Emotions On Satisfaction. International Journal Of Health Care Quality Assurance, 21 (1):108-134

Mulyo, Setyawan. 2007. Pengaruh Kualitas Layanan, Kepercayaan Dan Komitmen Terhadap Loyalitas Nasabah ( Studi Pada Pd. Bpr Bank Pasar Kendal). Jurnal Bisnis Dan Ekonomi (JBE), 14 (2):64-82 
Martin, D., Molina, A., dan Esteban, A. 2007. AndIntegrated Model Of Price, Satisfaction and Loyalty: An Empirical Analysis In The Service Sector, Journal of Product and Brand Management, 16 (7):459-478.

Murwatiningsih. dan E.P.Apriliani. 2013. Pengaruh Risiko Dan Harga Terhadap Keputusan Pembelian Melalui Kepercayaan Konsumen. Jurnal Dinamika Manajemen, 4 (2):184-191

Morgan, RM And Hunt, S.D, 1994, The Commitment-Trust Theory Of Relationship Marketing, Journal Of Marketing, 58 (2)20-38.

Prasastono.2016. Kualitas Produk dan Kualitas Pelayanan terhadap konsumen kentucky fried chicken Semarang Candi, Jurnal Stikubank Semarang.

Pitta, D., Franzak, F., and Fowler, D. 2006. A strategic approach to building online customer loyalty: integrating customer profitability tiers. Journal of Consumer Marketing, 23 (7):421-429.

Raje, Archana., and Vandana, Tandon Khanna. 2012. Impact of E-Service Quality on Consumer Purchase Behaviour in an On-line Shopping. IJCSMS International Journal of Computer Science and Management Studies, 12 (2):1-5.

Saha, G.C and Theingi 2009, Service quality, satisfaction, and behavioural intentions A study of low-cost airline carriers in Thailand, Managing Service Quality, 19 (3):350-372.

Singh, J. 2000. Agency And Trust Mechanisms In Customer Satisfaction And Loyalty Judgments. Journal Of The Academy Of Marketing Science, 28 (1):150-167.

Shyh-Jane Li. 2011. How Satisfaction Modifies The Strength Of The Influence Of Perceived Service Quality On Behavioral Intentions. Leadership In Health Services, 24 (2):46-70

Sujana, Ciptadi 2016. Peran Kepercayaan Dalam Memediasi Pengaruh Kualitas Situs Terhadap Niat Konsumen Untuk Berbelanja Di Situs Zalora. E-Jurnal Manajemen Unud. 5 (1):1-28

Tjiptono, Fandi. 2007. Pemasaran Jasa. Malang: Bayu Media

Tjiptono, Fandi Dan Georgerius Chandra. 2011. Service, Quality \& Satisfaction. Edisi Ketiga. Yogyakarta: Andi Offset. 
Wulandari, Sari. 2015. Peran Kepercayaan Dalam Memediasi Persepsi Nilai Terhadap Niat Beli Produk Ramah Lingkungan. E-Jurnal Manajemen Unud, 4 (7):1-30

Yunianta, Eka. 2015. Peran Kepercayaan Tamu Dalam Memediasi Pengaruh Kepuasan Konsumen Terhadap Loyalitas Pelanggan Hotel Taman Agung. E-Jurnal Manajemen Unud, 4 ( 4):1-26

Yiing Jaing,Chang LuaWang. 2006. The Impect Of AffectOn Servce Quality And Satisfaction: The Moderation OfService Contexts. Journal Of Services Marketing, 20 (4):1-25 